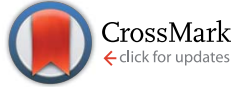

Cite this: RSC Adv., 2017, 7, 4108

\title{
Conversion of corn stover alkaline pre-treatment waste streams into biodiesel via Rhodococci $\dagger$
}

\author{
Rosemary K. Le, $t^{\mathrm{ab}}$ Tyrone Wells Jr., $\neq^{\mathrm{ab}}$ Parthapratim Das, ${ }^{\text {ab }}$ Xianzhi Meng, ${ }^{\text {ab }}$ \\ Ryan J. Stoklosa, ${ }^{\text {cd }}$ Aditya Bhalla, de David B. Hodge, ${ }^{\text {cdf Joshua S. Yuan }}{ }^{g}$ \\ and Arthur J. Ragauskas*abh
}

The bioconversion of second-generation cellulosic ethanol waste streams into biodiesel via oleaginous bacteria is a novel optimization strategy for biorefineries with substantial potential for rapid development. In this study, one- and two-stage alkali/alkali-peroxide pretreatment waste streams of corn stover were separately implemented as feedstocks in $96 \mathrm{~h}$ batch reactor fermentations with wild-type Rhodococcus opacus PD 630, R. opacus DSM 1069, and R. jostii DSM 44719 ${ }^{\top}$. Here we show using ${ }^{31} \mathrm{P}-\mathrm{NMR}, \mathrm{HPAEC}-$ $P A D$, and SEC analyses, that the more rigorous and chemically-efficient two-stage chemical pretreatment effluent provided higher concentrations of solubilized glucose and lower molecular weight ( 70-300 $\mathrm{g} \mathrm{mol}^{-1}$ ) lignin degradation products thereby enabling improved cellular density, viability, and oleaginicity in each respective strain. The most significant yields were by $R$. opacus PD 630, which converted $6.2 \%$ of organic content with a maximal total lipid production of $1.3 \mathrm{~g} \mathrm{~L}^{-1}$ and accumulated $42.1 \%$ in oils based on cell dry weight after $48 \mathrm{~h}$.

Received 10th December 2016 Accepted 15th December 2016

DOI: 10.1039/c6ra28033a

www.rsc.org/advances the total oil demand and is projected to steadily grow by $1.8 \%$ per year towards 2035; approximately $80 \%$ of energy in this sector is dedicated strictly to road transport. ${ }^{4}$ Hence, the development of renewable transportation energy has been a growing and apt target for sustainability research. ${ }^{4}$ Accordingly, advanced transportation biofuels sourced from renewable lignocellulosic biomass will, in part, better leverage limited energy resources as well as address security and environmental issues that will arise as demands for fuel increase. ${ }^{5}$ Specifically, advanced biofuels sourced from inedible second-generation agricultural feedstocks and biorefinery waste streams will be key to further optimizing plant-to-fuel processes while uniquely circumventing public concerns regarding the food $v s$. fuel debate. ${ }^{6-8}$

Advanced transportation biofuels are composed of two distinct categories: liquid alcohol-based fuels that include butanol and ethanol, and diesel-like hydrocarbon-based fuels such as biodiesel. ${ }^{9}$ Together, bioethanol and biodiesel are the most commonly blended liquid biofuels used in modern global transportation markets at roughly 150 billion liters per annum, an output that is predicted to nearly double by 2021 and address roughly $25 \%$ of worldwide transport fuel demand by $2050 .^{10,11}$ Bioethanol is commonly produced from the fermentation of sugar or starch largely sourced from plant biomass (e.g. energy crops, agricultural residues, wood materials, etc.). ${ }^{12}$ Alternatively, biodiesel is a product of the transesterification of triacylglycerides (TAG) typically sourced from animal fats and plant oils into long chain fatty acid methyl esters (FAME). ${ }^{\mathbf{4 , 1 0 , 1 1}}$ Although the use of bioethanol as a supplemental liquid fuel 
additive is noteworthy, the comparative energy density (26.8 MJ $\mathrm{kg}^{-1}$ ) is roughly $60 \%$ of pure gasoline $\left(46 \mathrm{MJ} \mathrm{kg}^{-1}\right)$, and the extent of blending is limited in some countries due to an incompatible dated transportation infrastructure. ${ }^{13,14}$ Comparatively, the energy density of biodiesel $\left(38 \mathrm{MJ} \mathrm{kg}^{-1}\right.$ ) is $\sim 84 \%$ compared to diesel $\left(45 \mathrm{MJ} \mathrm{kg}^{-1}\right)$ and can be used as a compatible fungible fuel for existing diesel engines. ${ }^{15}$ Despite this, sourcing biodiesel at commercial scale is often inhibited by the cost of limited production capacity. ${ }^{16,17}$ Interestingly, the conversion of biorefinery waste streams into biodiesel can provide a strategic avenue to better optimize biofuel production..$^{18,19}$

The use of microbial autotrophs (e.g. algae) and heterotrophs (e.g. fungi and bacteria) that can accumulate intracellular lipids for the sake of biodiesel production is a rapidly growing area of study towards biorefinery optimization..$^{20,21}$ While algae- and yeast-to-biofuel processes are prominent and are continuously being refined, oil-producing bacteria that are well-adapted for the degradation of plant biomass, also boasting a broader threshold of viable nutrients and tolerable growth conditions, represent an area of research with considerable potential for advancement. ${ }^{17,18,22,23}$ The genera of bacteria used in this work commonly include Acinetobacter, Mycobacterium, Streptomyces, and more recently Rhodococcus. ${ }^{24} R$. opacus and $R$. jostii have extensively been studied in the last few years and are well noted for their ability to accumulate oleaginous extents of intracellular single cell oils based on cell dry weight $(\mathrm{CDW})>20 \%$. For example, $R$. opacus PD 630 has exhibited high rates of oleaginicity (lipids per cell dry weight), above $80 \%$ CDW, when utilizing glucose as a carbon source under nitrogen-limited conditions. ${ }^{24,25}$ Beyond glucose, these wild-type species have also demonstrated the effective degradation of aromatic material common in lignocellulosic biomass, specifically, substituted aryl species found in lignin. The biochemical degradation of aryl units into lipids is made feasible via enzymemediated sequences such as the $\beta$-ketoadipate pathway ( $\beta$ KAP) ${ }^{26}$ For example, $R$. jostii was previously shown to accumulate over $55 \% \mathrm{CDW}$ in TAG utilizing benzoate as a carbon source, which is a comparable analog of lignin depolymerization products. ${ }^{27}$ Furthermore, $R$. opacus strains PD 630 and DSM 1069 have been shown to exercise the $\beta$-KAP pathway to utilize highly purified kraft lignin as a sole source of carbon and energy, albeit with limited extents of oleaginicity $(<5.0 \% \mathrm{CDW})$, which was attributed to the recalcitrant nature of lignin.

Pretreatment methodologies for cellulosic ethanol are being implemented in order to degrade, solubilize, and reduce the integrity of the lignin-hemicellulose matrix, thereby providing greater access to cellulose fibers for subsequent bioethanol processing. ${ }^{28,29}$ For example, standalone alkali pretreatment strategies have been designed to degrade and solubilize lignin and hemicellulose with corn stover. ${ }^{30-33}$ These alkali processes are being further optimized for industrial application ${ }^{33-39}$ and have been reviewed by Kim et $a l .^{40}$ The efficacy of a multi-stage pretreatment processes involving alkali pre-extraction with alkaline-oxidative post-treatments with corn stover has been investigated by Liu et al. and demonstrated that mild $\mathrm{NaOH}$ preextraction $\left(<100{ }^{\circ} \mathrm{C}\right)$ followed by alkali-hydrogen peroxide postextraction (ALK-AHP) significantly reduced the amount of required active chemical agents needed to extract lignin. ${ }^{33}$ ALKAHP pretreated corn stover also exhibited improved enzyme digestibility and fermentability towards second generation bioethanol production over standalone alkali processing (ALK). ${ }^{33}$

Notably, both the standalone ALK and two-stage ALK-AHP pretreatments generate an aqueous waste effluent fraction that contains low molecular weight lignin oligomers and carbohydrate content that could be further suited as a substrate

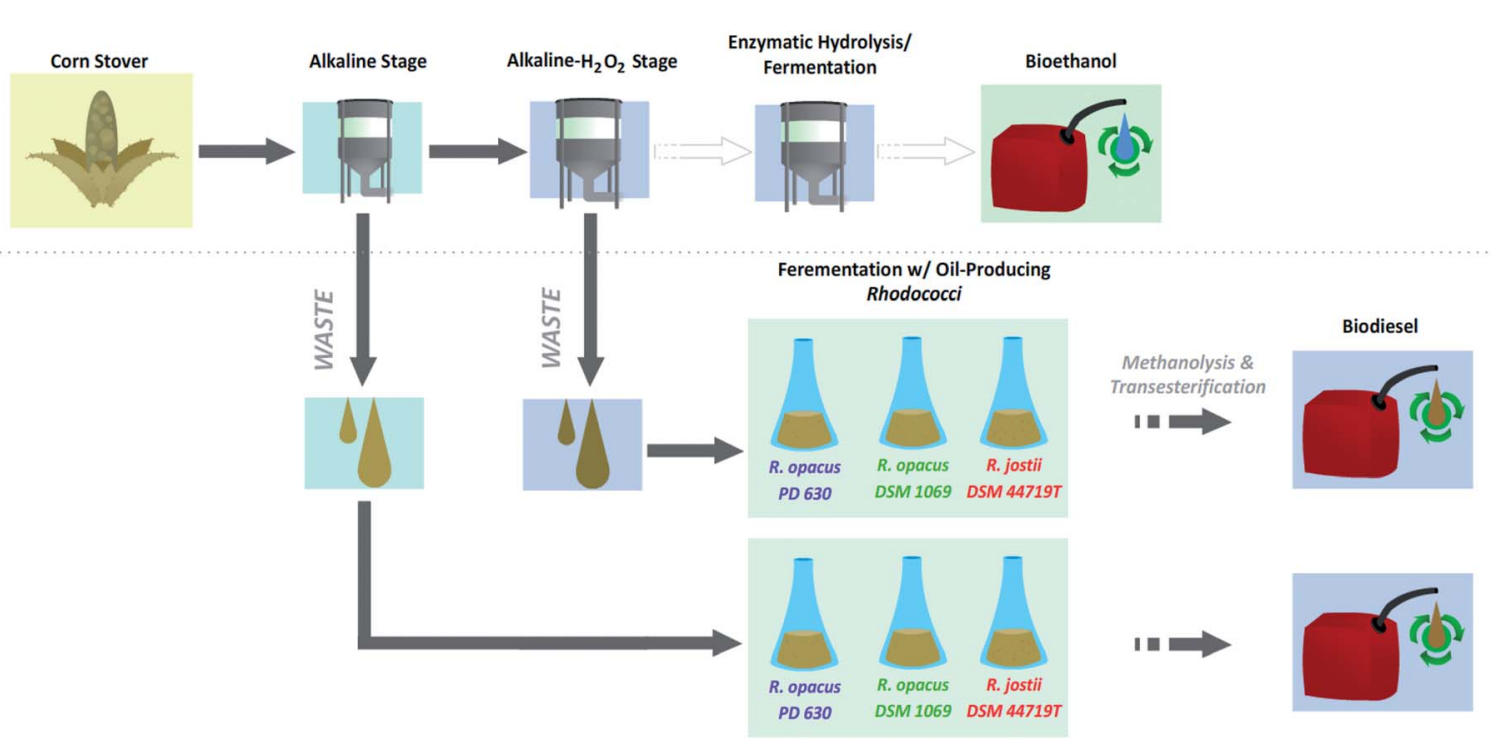

Fig. 1 Optimization of biorefinery processes via converting waste effluents into biodiesel. Corn stover biomass is processed via either by a standalone alkaline pretreatment or a subsequent by a alkaline-hydrogen-peroxide pretreatment step towards enzymatic bioprocessing that can ultimately yield bioethanol. The effluents generated by these processes are separately utilized as feedstocks by oleaginous by various Rhodococci to yield intracellular triacylglycerols that can be transesterified into fatty acid methyl esters with direct applicability as fungible biodiesel. 
for oleaginous Rhodococci towards biodiesel generation in a method that could substantially optimize biorefinery waste streams (Fig. 1). ${ }^{34,35}$ Several research groups have demonstrated the advantages in using alkaline pretreatment of biomass to yield effluents that can be utilized by microorganism to generate a variety of useful chemicals, including lipids in yeast ${ }^{\mathbf{4 1 , 4 2}}$ and plastic building block, polyhydroxyalkanoate in Pseudomonas putitda. ${ }^{43}$ Furthermore, work by Linger et al. and Katahira et al. have demonstrated that using alkaline or basecatalyzed pretreatments, which depolmerize lignin, produce low molecular weight aromatics, and yield a polysaccharide rich effluent. These low molecular weight molecules can then be biologically funneled by bacterial aromatic catabolic pathways to produce useful fuels and chemicals and overcome the intrinsically heterogeneous nature of lignin. ${ }^{\mathbf{4 3 , 4 4}}$

Due to the chemical-efficient and rigorous two-stage ALK-AHP treatment producing a superior feedstock effluent with enhanced concentrations of degraded lignin and carbohydrate products, we hypothesize this substrate will be more apt for microbial upgrading into biodiesel. We expect to see increased lipid yield compared to traditional standalone ALK pretreatment.

To investigate this matter, the efficacy of ALK and ALK-AHP pretreatment effluents (prepared as previously detailed) ${ }^{33}$ with corn stover (Zea mays L. Pioneer hybrid 36H56) as a feedstock for wild-type $R$. opacus PD 630, R. opacus DSM 1069, and $R$. jostii DSM $44719^{\mathrm{T}}$ was studied.

\section{Experimental}

\subsection{Corn stover feedstock}

Corn stover effluents were sourced from the Great Lakes Bioenergy Research Center (GLBRC) and harvested from the Arlington Research Facility in Wisconsin, USA. Untreated corn stover had a composition of $30.2 \%$ glucan, $18.5 \%$ xylan, $1.1 \%$ arabinan, 24.1\% Klason lignin, 6\% ASL, and 17.7\% ash, with $2.3 \%$ attributable to acetate groups. Alkali loading was $8 \%$ $\mathrm{NaOH}$ and solid-liquid separation was performed utilizing a 200 mesh stainless steel screen and centrifugation at $8000 \mathrm{rpm}$ for $5 \mathrm{~min}$ to remove fine particulates. Pretreatments were performed as previously detailed. ${ }^{33}$ Approximately $20.8 \%$ of total dry solids from the ALK effluent wash and 52.1\% ALKAHP effluent was non-ash content.

\subsection{Cell cultivation and monitoring}

Cell growth, assaying, monitoring, and methanolysis were performed based on previous literature.$^{45,46}$ Wild-type $R$. opacus $\mathrm{PD}$ 630, R. opacus DSM 1069, and R. jostii DSM $44719^{\mathrm{T}}$ were sourced from DSMZ and cultured following conventional methods. ${ }^{46}$ After an initial adaptation period of $48 \mathrm{~h}$ in the ALK and ALKAHP effluents at $\mathrm{pH} 7.2,40.0 \mathrm{mg} \mathrm{mL}^{-1} \mathrm{w} / \mathrm{v}$ solids loading, amended with minimal salt medium, ${ }^{39}$ and $0.1 \% \mathrm{w} / \mathrm{v}$ nitrogen content, the effluents were implemented as a sole source of energy and carbon under nitrogen-limited conditions $(\mathrm{pH} 7.2$, $40.0 \mathrm{mg} \mathrm{mL} \mathrm{m}^{-1}, 0.05 \mathrm{w} / \mathrm{v} \%$ nitrogen content) in a separate and parallel series of $96 \mathrm{~h}$ batch reactor fermentations $(150 \mathrm{~mL})$ to analyse the composition of intracellular lipids produced during the exponential and stationary phases of cell growth; the duration of these phases were resolved by tracking the cell density via optical density measurements taken at $600 \mathrm{~nm}$ $\left(\mathrm{OD}_{600}\right)$ and were determined to occur within 0-24 $\mathrm{h}$ and 24$72 \mathrm{~h}$, respectively (Fig. 2).

\subsection{Instrumental analyses}

Sugar release of monosaccharides was quantified using high performance anion exchange chromatography with pulsed amperometric detection (HPAEC-PAD). Specifically, a Dionex ICS-3000 ion chromatography with CarboPac PA-1 column was implemented. The temperature of the column was set to $23{ }^{\circ} \mathrm{C}$ and the eluents A and B were $100 \%$ DI water $(18 \mathrm{M} \Omega \mathrm{cm})$ and $200 \mathrm{mM} \mathrm{NaOH}$, respectively. The flow rate was set to $0.3 \mathrm{~mL}$ $\min ^{-1}$. Triplicate samples of the fermentation broths were analyzed and each analyte was quantified using linear regression based on calibration curves of an external standard of glucose, xylose, mannose, galactose, and arabinose based on a 1 $\times 10^{-3}$ to $1 \times 10^{-1} \mathrm{mg} \mathrm{mL}^{-1}$ concentrations were used with an $R^{2}$ values calculated above 0.995 (following NREL/TP-51042618). Errors associated with Dionex monosaccharide concentration determinations were below $\pm 1 \%{ }^{46}$
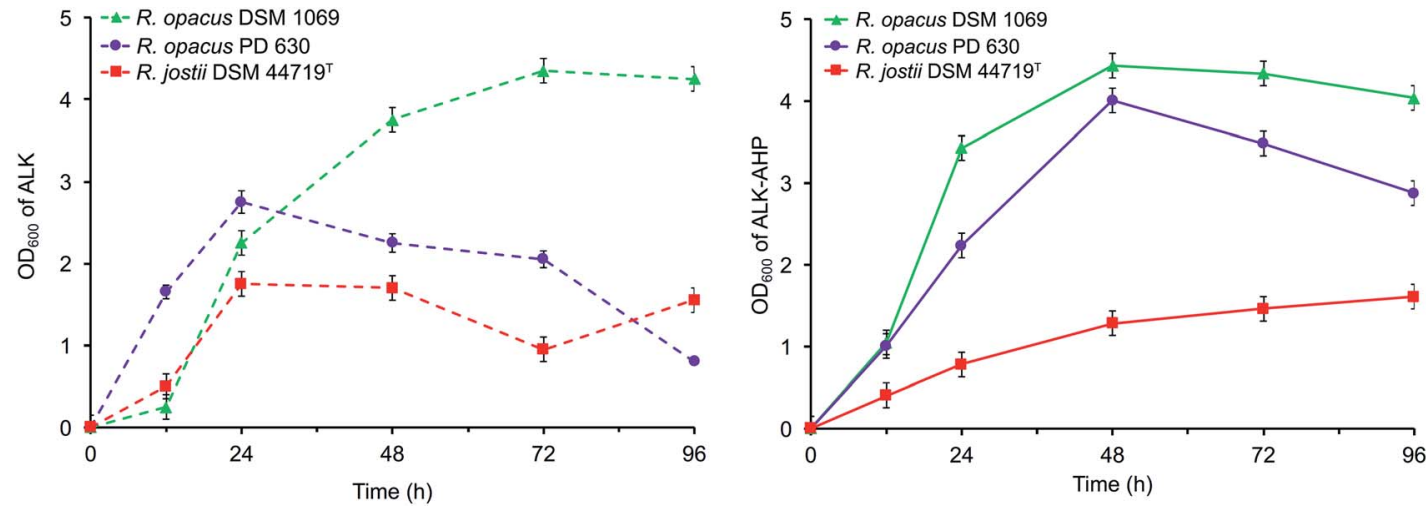

Fig. 2 Optical density measurements of Rhodococci in ALK (left) and ALK-AHP (right). 


\begin{abstract}
${ }^{31} \mathrm{P}$ NMR analysis of the lignin samples was resolved according to previous studies. ${ }^{47}$ In brief, endo- $N$-hydroxyl-5-norbornene-2,3dicarboximide, $\mathrm{Cr}(\mathrm{III})$ acetylacetonate and 2-chloro-4,4,5,5tetramethyl-1,3,2-dioxaphospholane were used as the internal standard, relaxation and phosphitylating agent, respectively. Spectra were collected on a Bruker Avance III $400 \mathrm{MHz}$ NMR spectrometer (fitted with a $5 \mathrm{~mm}$ Broadband Observe probe) that utilized an inverse-gated decoupling pulse sequence with a $90^{\circ}$ pulse. The spectra were run for 64 scans with $1 \mathrm{~s}$ acquisition time, a delay time of $25 \mathrm{~s}$, and referenced with respect to the residual water peak in the NMR solvent at $132.2 \mathrm{ppm}$.

GC-MS procedures were followed as described elsewhere. ${ }^{48}$ Likewise, SEC (size exclusion chromatography) analysis was performed as described previously. ${ }^{49}$ In detail, molecular mass distributions of the acetylated lignin samples were then analysed with an Agilent GPC SECurity 1200 system equipped with four Waters Styragel columns (HR1, HR2, HR4, HR6), and an Agilent UV detector set to $270 \mathrm{~nm}$, using tetrahydrofuran (THF) as the mobile phase $\left(1.0 \mathrm{~mL} \mathrm{~min}^{-1}\right)$, and an injection volume of $20.0 \mu \mathrm{L}$. A standard polystyrene sample was used for calibration.
\end{abstract}

\section{Results and discussion}

\subsection{Tracking cellular growth}

The data showed that the approximate optical cell densities of R. jostii DSM $44719^{\mathrm{T}}$ were largely consistent in either ALK or ALK-AHP effluent, but significantly lower than the two R. opacus strains as shown in Fig. 2. In ALK media, the absorbance of PD 630 and DSM 1069 were 1.2 and 2.2-fold greater than DSM $44719^{\mathrm{T}}$ at $48 \mathrm{~h}$, the median point of incubation, respectively. Moreover, when using ALK-AHP, the approximate cell densities of PD 630 and DSM 1069 were more improved at roughly 3.5fold higher than DSM $44719^{\mathrm{T}}$ at the same time period. In summary, the cell densities were improved with ALK-AHP as the feedstock and particularly for PD 630 and DSM 1069. Additionally, fluctuations of cell dry weight (CDW) as an estimate of total cell biomass per volume $\left(\mathrm{mg} \mathrm{mL}^{-1}\right)$ were measured, which complimented $\mathrm{OD}_{600}$ data, in that the optimal cell density and cell dry weight occurred at approximately $48 \mathrm{~h}$, and is illustrated and detailed in ESI Fig. 1. $\uparrow$ The CDW was significantly higher for ALK-AHP, which reached maxima of 2.13, 2.02 and $1.10 \mathrm{mg}$ $\mathrm{mL}^{-1}$ for PD 630, DSM 1069, and DSM $44719^{\mathrm{T}}$ at $48 \mathrm{~h}$. In contrast, dry cells per volume for strains grown in ALK media remained below $0.30 \mathrm{mg} \mathrm{mL}^{-1}$ throughout $96 \mathrm{~h}$ of incubation, thereby supporting that ALK-AHP effluent was the more optimal substrate for the propagation of cellular biomass.

To assess cell viability, optical density measurements $\left(\mathrm{OD}_{600}\right)$ and the concentration of colony forming units per $\mathrm{mL}$ (CFU $\mathrm{mL}^{-1}$ ) was monitored via serial dilute plating (SDP), illustrated in Fig. 2 and 3, respectively. As shown by $\mathrm{OD}_{600}$ and SDP, the viability of DSM $44719^{\mathrm{T}}$ was the lowest of the three strains and particularly consistent in either media while viability of cells grown in ALKAHP media were distinctly improved, particularly for PD 630 . When utilizing ALK effluent as a substrate, both PD 630 and DSM 1069 reached CFU mL ${ }^{-1}$ concentrations of a magnitude of $10^{5}$ after $12 \mathrm{~h}$ of incubation, compared to DSM $44719^{\mathrm{T}}$, which exhibited a magnitude of $10^{4}$. At $24 \mathrm{~h}$, near the end of the exponential phase, DSM 1069 displayed the highest viability with ALK effluents $\left(7.7 \times 10^{7} \mathrm{CFU} \mathrm{mL}^{-1}\right)$ while, at the same period, PD 630 exhibited the highest viability for ALK-AHP effluents $\left(7.6 \times 10^{7}\right.$ $\mathrm{CFU} \mathrm{mL}^{-1}$ ) as shown in Fig. 3. In contrast, $\mathrm{CFU} \mathrm{mL}{ }^{-1}$ for DSM $44719^{\mathrm{T}}$ cells principally remained within a magnitude of $10^{4}$ for 12-72 h with both feedstocks. This result suggests that both effluent feedstocks were capable of supporting the proliferation of new Rhodococci cells. Notably, while both $R$. opacus strains exhibited substantial increases in cell density when utilizing ALKAHP as an effluent from $0-48 \mathrm{~h}$, the viability of PD 630 was markedly improved over DSM 1069 (and consequently DSM $44719^{\mathrm{T}}$ ) during the same interval, which may support that PD 630 experienced the most optimal growth, overall, of the three strains based on cellular density and viability.

\subsection{Tracking of lipid yields}

Using gas chromatography-mass spectrometry (GC-MS), the total yield of FAME $\left(\mathrm{mg} \mathrm{L}^{-1}\right)$ and the resultant oleaginicity (\% CDW, lipids per cell dry weight) of each strain were calculated. Overall, the yield of FAME and oleaginicity were substantially improved with ALK-AHP effluent as a feedstock compared to ALK effluent as summarized in Fig. 4. In detail, when ALK-AHP effluent was implemented as a substrate, PD 630 exhibited the
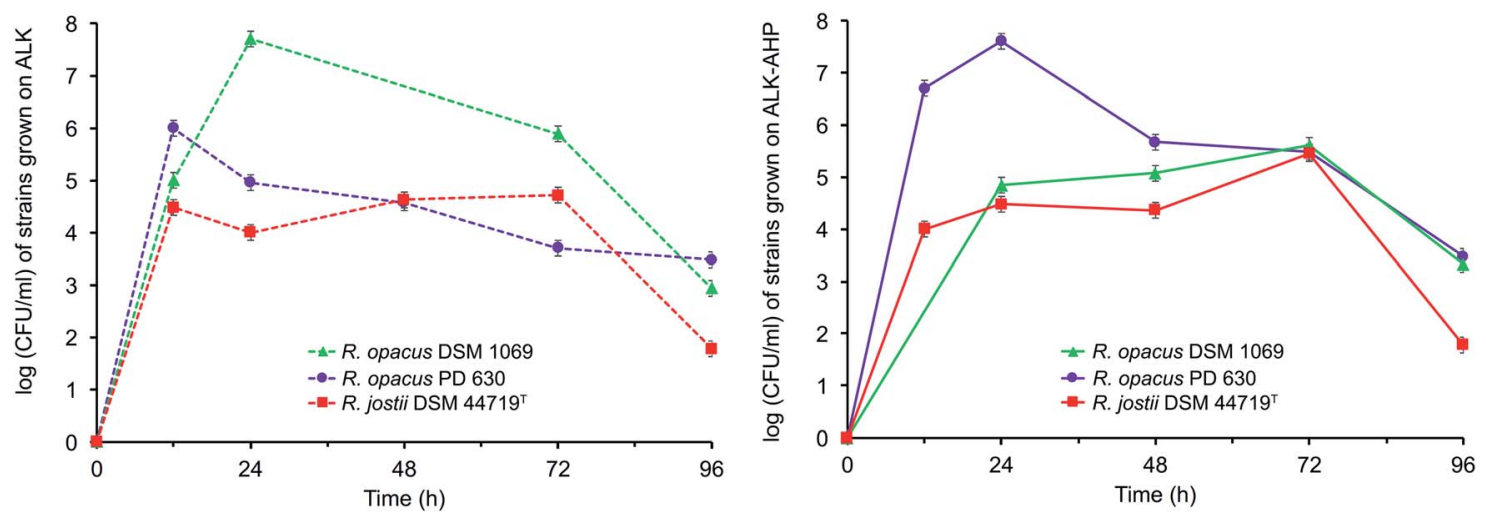

Fig. 3 Viability measurements of Rhodococci in ALK (left) and ALK-AHP (right). 


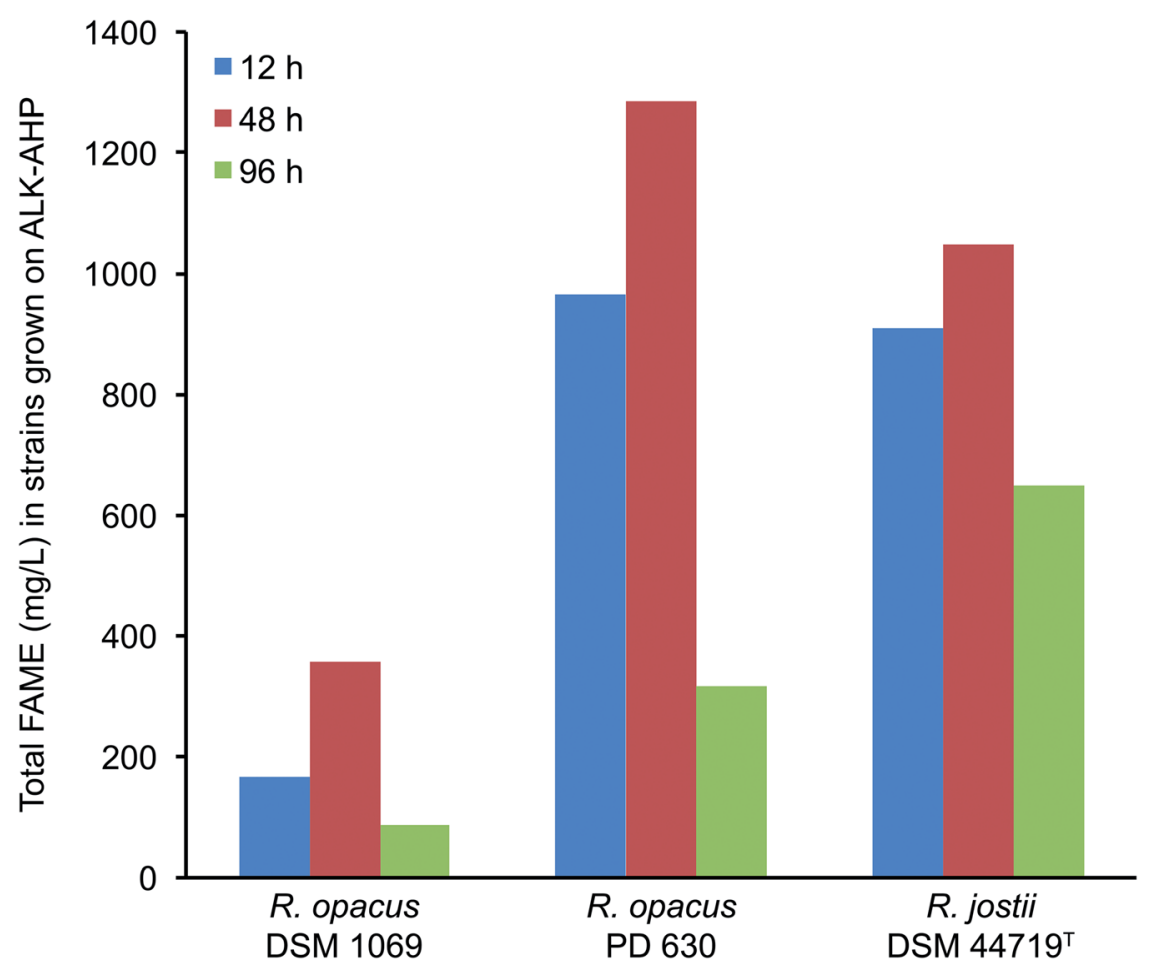

Fig. 4 Total FAME production by Rhodococci strains using ALK-AHP effluent. Largest overall yields were exhibited by R. opacus PD 630, followed by $R$. jostii DSM 44719 ${ }^{\top}$ and R. opacus DSM 1069.

highest total FAME and oleaginicity $\left(1.28 \mathrm{~g} \mathrm{~mL}^{-1}, 42.1 \%\right)$ at $48 \mathrm{~h}$. Interestingly, at this same period, DSM $44719^{\mathrm{T}}$ exhibited the second highest yield of FAME and oleaginicity $\left(1.05 \mathrm{~g} \mathrm{~mL}^{-1}\right.$; $23.3 \%)$ despite exhibiting lower cell density and viability compared to DSM 1069 (358.5 mg L $\left.{ }^{-1} ; 12.6 \%\right)$. These results indicate that under the given conditions, DSM 1069 was more adept at generating cells while DSM $44719^{\mathrm{T}}$ more effectively accumulated lipids. Meanwhile, R. opacus PD 630 showcased the comparatively higher concentrations of viable cells and oleaginicity yields. In contrast, when ALK was the feedstock, lipid yields were 100-, 175-, and 180-fold lower for DSM 1069, PD 630 , and DSM $44179^{\mathrm{T}}$, respectively. Overall, total FAME production and oleaginicity on the ALK effluent were universally $<16 \mathrm{mg} \mathrm{L}^{-1}$ and $<0.5 \%$, respectively with the most substantial outcome exhibited by DSM $1069\left(15.7 \mathrm{mg} \mathrm{L}^{-1}, 0.4 \%\right)$ after $96 \mathrm{~h}$ of incubation. This finding is consistent to the extent that DSM 1069 displayed the most optimal growth in ALK media based on $\mathrm{OD}_{600}$, $\mathrm{CDW}$, and $\mathrm{CFU} \mathrm{mL}^{-1}$ data. In all cases, the resulting FAME were determined to be enriched with palmitic (hexadecanoic), stearic (octadecanoic), and oleic acids, which is consistent with previous reports involving wild-type Rhodococci. $^{45} \mathrm{~A}$ detailed distribution of the amount and variety of FAME produced during cell proliferation on the ALK and ALKAHP effluents are shown in ESI Tables 1-3.†

\subsection{Tracking changes in monomeric glucose and molecular weight distribution}

A comprehensive characterization of the feedstock broths was performed to determine changes of the degradation materials present during pretreatment. For example, alkaline corn stover pretreatments at moderate conditions $\left(<100{ }^{\circ} \mathrm{C}\right)$ can release oligomeric fragments of lignin as well as hemicelluloses such as glucan and xylan along with monomeric glucose. ${ }^{33}$ As previously detailed, glucose can be targeted as a key metabolic unit by oleaginous Rhodococci. ${ }^{24,46}$ Hence, high-performance anionexchange chromatography with pulsed amperometric detection (HPAEC-PED, Dionex, Sunnyvale, CA, USA) was used to track the concentrations of glucose monomers during the initial, median, and final hour of incubation. Ultimately, it was determined that the initial concentrations of glucose were 4.5fold higher in the multistage ALK-AHP effluent $\left(5.82 \mathrm{mg} \mathrm{mL}^{-1}\right)$ compared to the standalone ALK effluent $\left(1.25 \mathrm{mg} \mathrm{mL}^{-1}\right)$. These concentrations universally declined from $0-96 \mathrm{~h}$ to values below $1.00 \mathrm{mg} \mathrm{mL}^{-1}$ for both effluents as illustrated in Fig. 5(a). The tracking of other sugars are detailed in ESI Fig. 2(a)-(c). $\dagger$ For example, in ALK-AHP, DSM 1069 nearly depleted solubilized glucose to a threshold below $1.00 \mathrm{mg} \mathrm{mL}^{-1}$ within $0-48 \mathrm{~h}$ and PD 630 and DSM $44719^{\mathrm{T}}$ reached this threshold during the 48$96 \mathrm{~h}$ interval; this result concurs with the respective order at which viability was observed to significantly depreciate for each strain as cells likely transitioned to alternative constituents.

Size exclusion chromatography (SEC) was preformed to further assess changes in the distribution of molecular mass of the effluent components before and after incubation with Rhodococci. As shown in Fig. 5(b) and (c), the initial molecular weight distribution profile of both effluents generally exhibited two distinct regions: a mono-modal low molecular weight peak $(100-300 \mathrm{~g}$ $\mathrm{mol}^{-1}$ ) and a multimodal shelf spanning $300-2500 \mathrm{~g} \mathrm{~mol}^{-1}$ for 


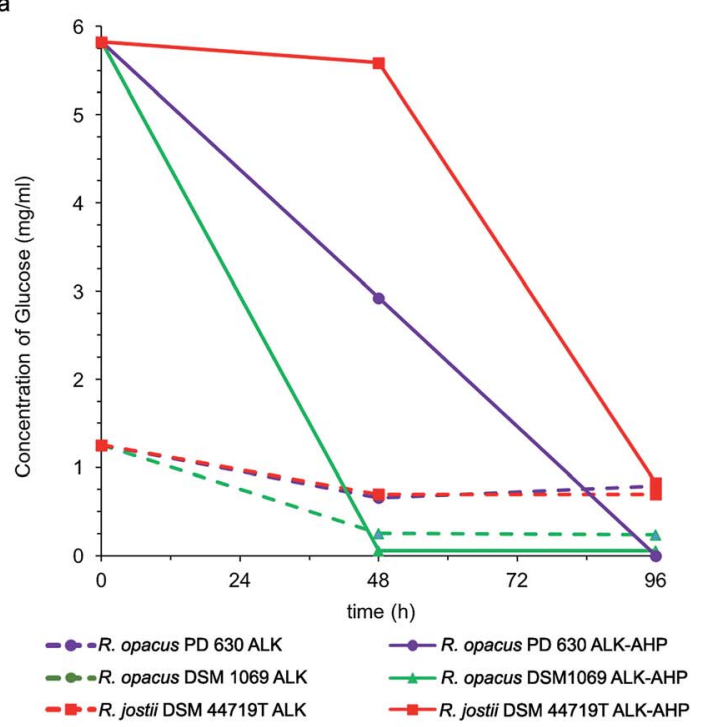

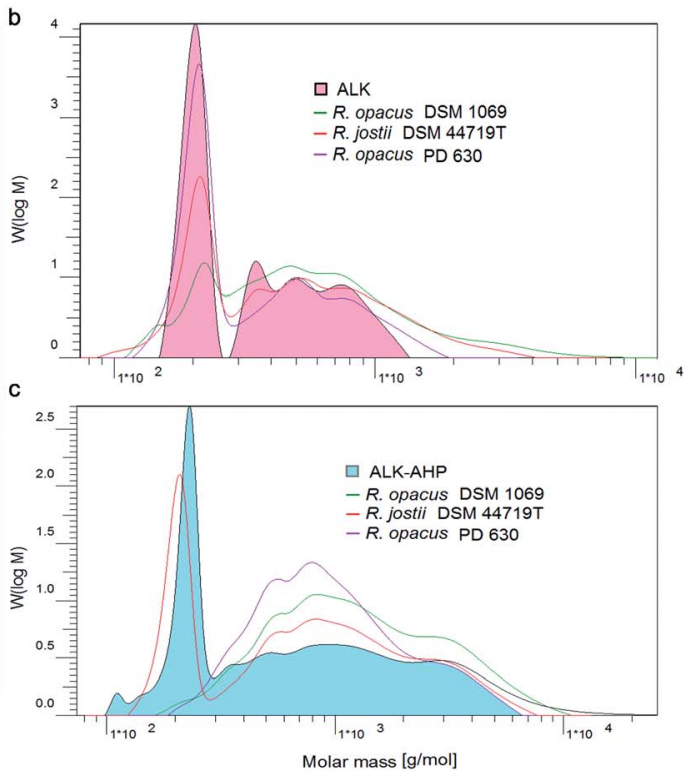

Fig. 5 Change in glucose concentration and molecular weight distributions in effluents. (a) The concentrations of solubilized glucose are illustrated using ALK effluent (dashed) and ALK-AHP effluent (solid) during $96 \mathrm{~h}$ of incubation with R. opacus PD 630 (purple), R. opacus DSM 1069 (green) and $R$. jostii DSM 44719 (red). After $96 \mathrm{~h}$, all samples reduced concentrations below $1 \mathrm{mg} \mathrm{mL}^{-1}$. (b-c) Changes in the molecular weight distribution profiles are shown in ALK (top, with the $0 \mathrm{~h}$ molar mass distribution profile shown in pink) and ALK-AHP (bottom, with $0 \mathrm{~h}$ shown in blue). Overlaid outlines depict changes after $96 \mathrm{~h}$ of incubation with $R$. opacus PD 630 (purple), R. opacus DSM 1069 (green), or $R$. jostii DSM $44719^{\top}$ (red).

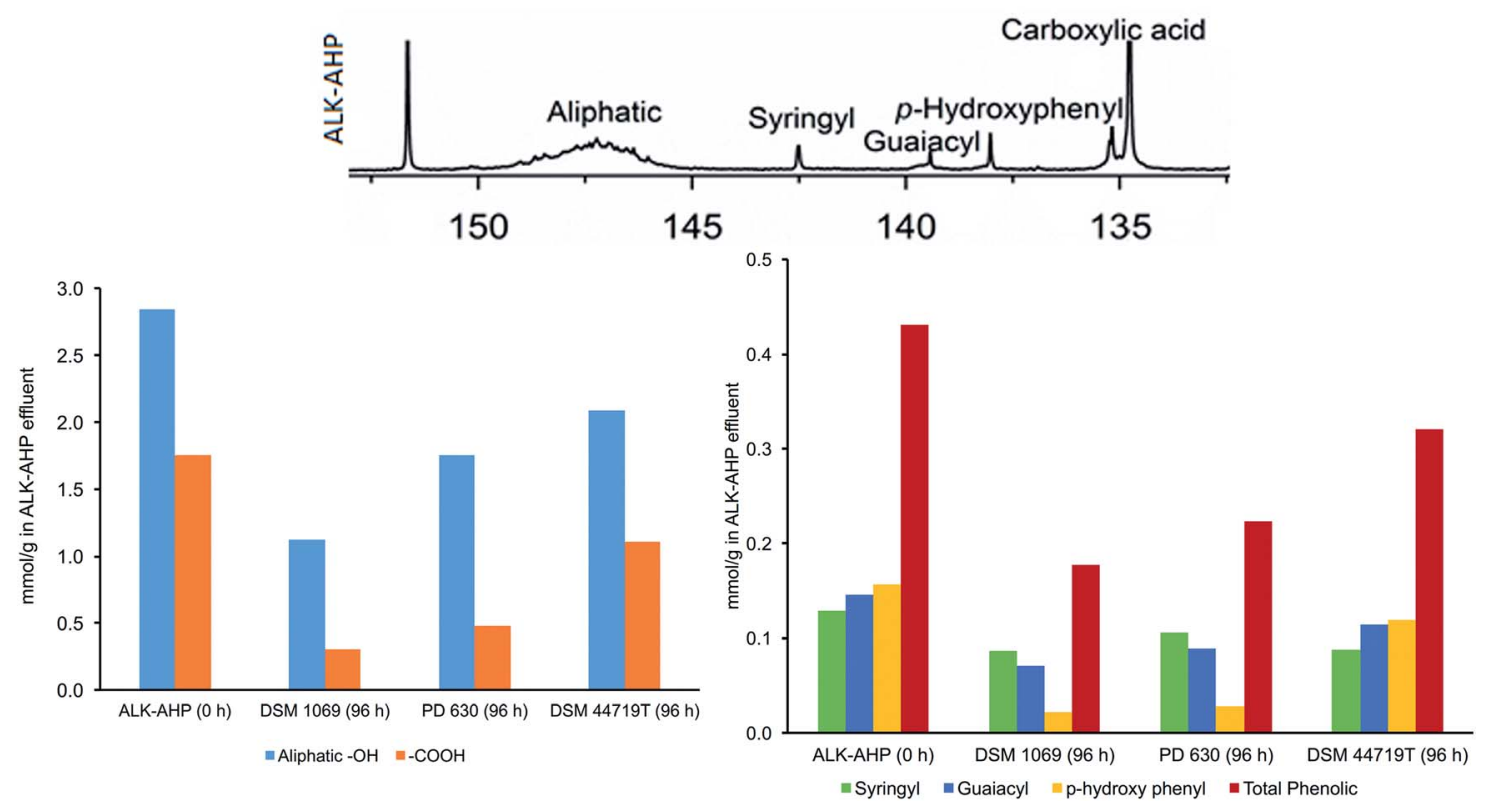

Fig. 6 Quantitative ${ }^{31} \mathrm{P}-\mathrm{NMR}$ results. The ${ }^{31} \mathrm{P}-\mathrm{NMR}$ spectra of ALK-AHP at $\mathrm{O} \mathrm{h}$ is shown above. Below are the results of integrated regions respective to aliphatic and carboxylic $-\mathrm{OH}$ groups (left) as well as syringyl, guaiacyl, p-hydroxyphenyl, and total phenolic $-\mathrm{OH}$ groups (right). Results for the standalone ALK effluent are provided in ESI. $\dagger$

ALK and 300-20 $000 \mathrm{~g} \mathrm{~mol}^{-1}$ for ALK-AHP. As expected, the more rigorous multistage pretreatment process yielded a substantially broader assortment of molecular weight components in the effluent. Overall, the most significant changes were observed in the $<300 \mathrm{~g} \mathrm{~mol}^{-1}$ regions. For example, DSM 1069 in ALK effluent displayed the most substantial depletion of low molecular weight constituents followed by DSM $44719^{\mathrm{T}}$ and PD 630, in that order. More thorough depletion of components smaller than $300 \mathrm{~g} \mathrm{~mol}^{-1}$ was observed when ALK-AHP effluent was used as a feedstock, especially by $R$. opacus PD 630 and DSM 1069. 


\section{4. ${ }^{31} \mathrm{P}-\mathrm{NMR}$ analysis}

${ }^{31} \mathrm{P}-\mathrm{NMR}$ analysis was performed on the ALK and ALK-AHP feedstock effluents before and after $96 \mathrm{~h}$ of incubation with Rhodococci to assess changes to solubilized lignin oligomers, illustrated in Fig. 6. Both effluents provided signals that were evident of grass-type lignin (GSH-lignin). In detail, syringyl(142.7 ppm), guaiacyl- (139.0-140.2 ppm), and parahydroxyphenyl-based (137.8 ppm) monolignol units were clearly resolved. ${ }^{47,50}$ The ALK-AHP feedstock had an initial $\sim 30 \%$ and $\sim 80 \%$ higher concentration of total phenolic and aliphatic content compared to ALK, respectively. Moreover, carboxylic hydroxyl groups were higher in ALK-AHP compared to ALK, which is expected of a more rigorous delignification process. ${ }^{36,51}$

After $96 \mathrm{~h}$ of incubation, all strains exhibited significant depletion of phenolic, aliphatic, and carboxylic regions, particularly by PD 630 and DSM 1069 when utilizing ALK-AHP as a substrate. The total phenolic content decreased by 58,48 , and $26 \%$ by DSM 1069, PD 630, and DSM $44719^{\mathrm{T}}$, respectively. Likewise, aliphatic $\mathrm{OH}$ content decreased by 60,38 , and $26 \%$ by DSM 1069, PD 630, and DSM 44719 ${ }^{\mathrm{T}}$, in that same order; furthermore, losses in carboxylic hydroxyl content were by 83 , $73,37 \%$ following the same succession. These results support that simultaneous degradation of lignin along with carbohydrates during incubation was evident in all strains of Rhodococci utilizing ALK-AHP as a substrate, particularly by the $R$. opacus strains. Using model compounds, it has been reported that DSM 1069 and PD 630 exhibit preferences towards parahydroxylphenyl, guaiacyl, and syringyl monolignol units, in that order. ${ }^{52}$ This may be due to the amount of energy required for demethoxylation in order to yield protocatechuate or catechol as initial metabolites for the $\beta$-KAP. ${ }^{52,53}$ Therefore, it is intriguing that the $R$. opacus strains, which both gained relatively substantial cell density in ALK-AHP media, exhibited a clear preference toward para-hydroxylphenyl units, followed by guaiacyl, and syringyl units. This observation is consistent with previous studies. ${ }^{\mathbf{4 6 , 5 2}}$ This feature was not observed for DSM $44719^{\mathrm{T}}$, which depleted approximately $25-30 \%$ of each phenolic type with no observable preference, and could be due to the lower degree of cell proliferation that occurred over the course of the experiment. In a similar manner, phenolic preference was generally irregular for Rhodococci grown on ALK substrates. The most noteworthy modifications were caused by DSM 1069 in ALK effluent, which exhibited the highest cell proliferation, and depleted a mere 15, 20, and 16\% of total phenolic, aliphatic, and carboxylic content, respectively (ESI Fig. $4 \dagger)$.

\section{Conclusions}

Multistage ALK-AHP, which couples alkaline pre-extraction with an alkaline hydrogen peroxide post-treatment, is a more chemical-efficient pretreatment strategy compared to standalone alkali pre-extraction that serves to enhance enzymatic hydrolysis and fermentability towards bioethanol production. Moreover, when compared to ALK, ALK-AHP produces an effluent stream that contains more solubilized components and serves as a more practical feedstock for microbial biodiesel production. In this work, it was reported that oleaginous wild-type Rhodococci can simultaneously catabolize glucose and low molecular weight $\left(<300 \mathrm{~g} \mathrm{~mol}^{-1}\right)$ compounds in ALK-AHP effluent and accumulate substantial yields of intracellular oils. Wild-type $R$. opacus PD 630 was the most optimal strain based on lipid production for a total FAME yield of $1.3 \mathrm{~g} \mathrm{~L}^{-1}$ and oleaginicity of $42.1 \%$, based on cell dry weight. Total organic content in ALK-AHP was determined to be $20.8 \mathrm{~g} \mathrm{~L}^{-1}$, of which $6.2 \%$ was converted into lipids by PD 630 after 48 h (ESI Table $3 \dagger$ ). The considerable amount of inorganic content was due to processing conditions of the primary feedstock and could be a concern with regard to cellular inhibition. Despite this, and even lacking metabolic engineering, the titer yields reported here are largely comparable to current benchmark of effective pathways established for biodiesel production in bacteria, which is approximately $\sim 1.5 \mathrm{~g} \mathrm{~L}^{-1}$ in fatty acid ethyl esters. ${ }^{54}$ Furthermore, the lipid titer in this work is a promising starting point for non-engineered Rhodococcus strains. In contrast with the work by Kurosowa et al. that showed that the $R$. opacus PD 630 could yield an optimal value of $25.2 \mathrm{~g}$ $\mathrm{L}^{-1}$ of fatty acids when grown on media containing $240 \mathrm{~g} \mathrm{~L}^{-1}$ glucose,$^{55}$ the ALK and ALK-AHP are suitable effluents that can balance growth and lipid accumulation on significantly less glucose, approximately 40 times less at, $1.2 \mathrm{~g} \mathrm{~L}^{-1}$ and $5.8 \mathrm{~g} \mathrm{~L}^{-1}$ glucose, respectively, initially, and the lignin was utilized, as seen by the transformation of the phenolic, aliphatic, and carboxylic groups present via NMR. These findings demonstrate that utilizing industrial effluents that contain a fraction of sugars and lignin to support cellular biomass generation could be an advantageous pathway for biofuel production that warrants further investigation into industrially-derived effluents containing low-molecular weight carbon sources, which could also be optimized if coupled with engineered oleaginous bacterial strains to target TAG production or other value-added targets.

\section{Acknowledgements}

The research team acknowledges the Department of Energy (DE-EE0006112) for funding the microbial conversion results reported in this manuscript.

\section{References}

1 Y. He, Y. Xu, Y. Pang, H. Tian and R. Wu, Renewable Energy, 2016, 89, 695-705.

2 S. Ahmed, A. Mahmood, A. Hasan, G. A. S. Sidhu and M. F. U. Butt, Renewable Sustainable Energy Rev., 2016, 57, 216-225.

3 B. D. Solomon, A. Banerjee, A. Acevedo, K. E. Halvorsen and A. Eastmond, Environ. Manage., 2015, 56, 1276-1294.

4 A. E. Atabani, A. S. Silitonga, I. A. Badruddin, T. Mahlia, H. Masjuki and S. Mekhilef, Renewable Sustainable Energy Rev., 2012, 16, 2070-2093. 
5 D. Tilman, R. Socolow, J. A. Foley, J. Hill, E. Larson, L. Lynd, S. Pacala, J. Reilly, T. Searchinger and C. Somerville, Science, 2009, 325, 270-271.

6 R. Singh, M. Srivastava and A. Shukla, Renewable Sustainable Energy Rev., 2016, 54, 202-216.

7 J. C. Liao, L. Mi, S. Pontrelli and S. Luo, Nat. Rev. Microbiol., 2016, 14, 288-304.

8 G. R. Timilsina and S. Mevel, Environ. Resour. Econ., 2013, 55, 1-19.

9 J. M. Bergthorson and M. J. Thomson, Renewable Sustainable Energy Rev., 2015, 42, 1393-1417.

10 I. Gelfand, R. Sahajpal, X. Zhang, R. C. Izaurralde, K. L. Gross and G. P. Robertson, Nature, 2013, 493, 514-517.

11 G. R. Timilsina, Philos. Trans. R. Soc., A, 2014, 372, 20120323.

12 A. Gupta and J. P. Verma, Renewable Sustainable Energy Rev., 2015, 41, 550-567.

13 L. Caspeta, N. A. Buijs and J. Nielsen, Energy Environ. Sci., 2013, 6, 1077-1082.

14 I. Hore-Lacy, Nuclear Energy in the 21st Century: World Nuclear University Press, Academic press, 2010.

15 Y. Chisti, Biotechnol. Adv., 2007, 25, 294-306.

16 M. K. Lam and K. T. Lee, Appl. Energy, 2012, 94, 303-308.

17 D. Pimentel and T. W. Patzek, Nat. Resour. Res., 2005, 14, 6576.

18 G. T. Beckham, C. W. Johnson, E. M. Karp, D. Salvachúa and D. R. Vardon, Curr. Opin. Biotechnol., 2016, 42, 40-53.

19 A. J. Ragauskas, C. K. Williams, B. H. Davison, G. Britovsek, J. Cairney, C. A. Eckert, W. J. Frederick, J. P. Hallett, D. J. Leak and C. L. Liotta, Science, 2006, 311, 484-489.

20 X. Miao and Q. Wu, Bioresour. Technol., 2006, 97, 841-846.

21 F. Deeba, V. Pruthi and Y. S. Negi, Bioresour. Technol., 2016, 213, 96-102.

22 J. A. Gomez, K. Höffner and P. I. Barton, Green Chem., 2016, 18, 461-475.

23 X. Meng, J. Yang, X. Xu, L. Zhang, Q. Nie and M. Xian, Renewable Energy, 2009, 34, 1-5.

24 H. M. Alvarez, R. Kalscheuer and A. Steinbuchel, Appl. Microbiol. Biotechnol., 2000, 54, 218-223.

25 H. M. Alvarez and A. Steinbuechel, Appl. Microbiol. Biotechnol., 2002, 60, 367-376.

26 T. Wells and A. J. Ragauskas, Trends Biotechnol., 2012, 30, 627-637.

27 S. Amara, N. Seghezzi, H. Otani, C. Diaz-Salazar, J. Liu and L. D. Eltis, Sci. Rep., 2016, 6, 24985.

28 A. J. Ragauskas and F. Huang, in Pretreatment Techniques for Biofuels and Biorefineries, Springer, 2013, pp. 151-179.

29 A. J. Ragauskas, G. T. Beckham, M. J. Biddy, R. Chandra, F. Chen, M. F. Davis, B. H. Davison, R. A. Dixon, P. Gilna, M. Keller, P. Langan, A. K. Naskar, J. N. Saddler, T. J. Tschaplinski, G. A. Tuskan and C. E. Wyman, Science, 2014, 344, 709.

30 K. L. Kadam and J. D. McMillan, Bioresour. Technol., 2003, 88, 17-25.

31 D. M. Alonso, S. G. Wettstein, J. Q. Bond, T. W. Root and J. A. Dumesic, ChemSusChem, 2011, 4, 1078-1081.

32 R. E. Sims, W. Mabee, J. N. Saddler and M. Taylor, Bioresour. Technol., 2010, 101, 1570-1580.
33 T. Liu, D. L. Williams, S. Pattathil, M. Li, M. G. Hahn and D. B. Hodge, Biotechnol. Biofuels, 2014, 7, 1.

34 Y. Yamashita, M. Shono, C. Sasaki and Y. Nakamura, Carbohydr. Polym., 2010, 79, 914-920.

35 B. C. Saha and M. A. Cotta, Biotechnol. Prog., 2006, 22, 449453.

36 M. Li, C. Foster, S. Kelkar, Y. Pu, D. Holmes, A. Ragauskas, C. M. Saffron and D. B. Hodge, Biotechnol. Biofuels, 2012, $5,38$.

37 D. Donald and G. Göran, in Lignin and Lignans, CRC Press, 2010, pp. 349-391, DOI: 10.1201/EBK1574444865c1010.1201/EBK1574444865-c10.

38 E. M. Karp, M. G. Resch, B. S. Donohoe, P. N. Ciesielski, M. H. O'Brien, J. E. Nill, A. Mittal, M. J. Biddy and G. T. Beckham, ACS Sustainable Chem. Eng., 2015, 3, 14791491.

39 B. Wang, Y. H. Rezenom, K.-C. Cho, J. L. Tran, D. G. Lee, D. H. Russell, J. J. Gill, R. Young and K.-H. Chu, Bioresour. Technol., 2014, 161, 162-170.

40 J. S. Kim, Y. Y. Lee and T. H. Kim, Bioresour. Technol., 2016, 199, 42-48.

41 Z. Gong, H. Shen, X. Yang, Q. Wang, H. Xie and Z. K. Zhao, Biotechnol. Biofuels, 2014, 7, 158.

42 M.-H. Joe, J.-Y. Kim, S. Lim, D.-H. Kim, S. Bai, H. Park, S. G. Lee, S. J. Han and J.-I. Choi, Biotechnol. Biofuels, 2015, 8, 125.

43 J. G. Linger, D. R. Vardon, M. T. Guarnieri, E. M. Karp, G. B. Hunsinger, M. A. Franden, C. W. Johnson, G. Chupka, T. J. Strathmann, P. T. Pienkos and G. T. Beckham, Proc. Natl. Acad. Sci. U. S. A., 2014, 111, 12013-12018.

44 R. Katahira, A. Mittal, K. McKinney, X. Chen, M. P. Tucker, D. K. Johnson and G. T. Beckham, ACS Sustainable Chem. Eng., 2016, 4, 1474-1486.

45 Z. Wei, G. Zeng, M. Kosa, D. Huang and A. J. Ragauskas, Appl. Biochem. Biotechnol., 2015, 175, 1234-1246.

46 T. Wells, Z. Wei and A. Ragauskas, Biomass Bioenergy, 2015, 72, 200-205.

47 Y. Pu, S. Cao and A. J. Ragauskas, Energy Environ. Sci., 2011, 4, 3154-3166.

48 M. Kosa and A. J. Ragauskas, Green Chem., 2013, 15, 20702074.

49 T. Wells, M. Kosa and A. J. Ragauskas, Ultrason. Sonochem., 2013, 20, 1463-1469.

50 R. John and L. L. Larry, in Lignin and Lignans, CRC Press, 2010, pp. 137-243, DOI: 10.1201/EBK1574444865c510.1201/EBK1574444865-c5.

51 J.-D. Mao, K. Holtman and D. Franqui-Villanueva, J. Agric. Food Chem., 2010, 58, 11680-11687.

52 M. Kosa and A. J. Ragauskas, Appl. Microbiol. Biotechnol., 2012, 93, 891-900.

53 T. Wells Jr and A. J. Ragauskas, Trends Biotechnol., 2012, 30, 627-637.

54 S. Sherkhanov, T. P. Korman, S. G. Clarke and J. U. Bowie, Sci. Rep., 2016, 6, 24239.

55 K. Kurosawa, P. Boccazzi, N. M. de Almeida and A. J. Sinskey, J. Biotechnol., 2010, 147, 212-218. 